\title{
Partial Replacement of Cement by Industrial Fly Ash as Binding Agent
}

\author{
Muhammad Moeen ${ }^{1}$, Qi Tian ${ }^{2 *}$, Muhammad Yaseen ${ }^{3}$, Abdul Nasir ${ }^{4}$, Zawar Hussain ${ }^{5}$, Mudassir Habib ${ }^{6}$ \\ ${ }^{1,2,5,6}$ College of Environmental Science and Engineering, Taiyuan University of Technology, Taiyuan 030024, China \\ ${ }^{1,2}$, School of Civil Engineering, Taiyuan University of Technology, Taiyuan 030024, China \\ ${ }^{1,3}$ Institute of Soil and Environmental Sciences, University of Agriculture, Faisalabad, 38000, Pakistan \\ ${ }^{4}$ Department of Structure and Environmental Engineering, University of Agriculture, Faisalabad, 38000, Pakistan \\ moeenejaz79@gamil.com¹,412559908@qq.com², dr.yaseen@gmail.com ${ }^{3}$, anawan@uaf.edu.pk ${ }^{4}$, \\ hussain.zawar1292@ hotmail.com ${ }^{5}$, mudassirhabib62@yahoo.com ${ }^{6}$ \\ Received: 16 December, Revised: 26 December, Accepted: 28 December
}

\begin{abstract}
Concrete is the key component that is usually used in construction as in the world containing 70-75 percent of natural rocks, sand and 10-15 percent of Ordinary Portland Cement (OPC). Concerns about global sustainability of construction technology and the efficient use of structural aggregates in concrete will help minimize construction problems. Because of the high cost of cement, construction has become more costly and due to $\mathrm{CO}_{2}$ pollution and other harmful heavy metals during the cement production process, it becomes environmentally dangerous, so we can partly replace the portend cement with fly ash created as solid waste by different industries and power generation plants. At dumping sites, this fly ash is dumped locally, causing air pollution. Because of its binding behavior, we use fly ash as a binding constituent. The purpose behind this research work was to evaluate the tensile and compressive strength of specimens while using different fly ashes in favor of environmentally friendly technique and to perform the properties of workout strength and the variation pattern with mixing in different proportions of different tests such as tensile and compressive strength after 7, 14, 21 and 28 days of healing. Cement was replaced by various types of ashes including coal ash, Vachellia nilotica (Kikar) ash, Dalbergia sisso (shisham) with different concentration of 10, 20, 30, 40 and $50 \%$ of each. Results showed that when $10 \%$ of coal ash, Vachellia nilotica (kikar) ash, Dalbergia sisso (shisham) was used, concrete and mortar tensile and compressive strength increased with the increase in healing time. While the decrease in intensity was observed in samples with proportions of 20, 30, 40 and $50 \%$ with the same healing time. In addition the samples with coal, Vachellia nilotica (Kikar) ash, Dalbergia sissoo (shisham) ash, a decreasing trend in strength along with weight decrease was observed. By using coal ash upto $10 \%$ can reduce the $13.5 \%$ construction cost without losing strength properties in concrete. Such building materials can be used in lightweight buildings such as farm buildings for poultry and dairy farm buildings.
\end{abstract}

Keywords - Fly Ash, Incubation Time, Tensile Strength, Compressive Strength.

\section{INTRODUCTION}

The use of concrete is a construction constituent and one of the oldest methods used in a modern world. Concrete is largest natural resources consuming, and is durable, strengthen and easily available. So the largest number of natural resources is being consumed by concrete industry. $10-15 \%$ of the cement based adhesives and $15 \%$ of water is included in the $70-75 \%$ of total concrete, while it is estimated that annual production of concrete is 37-41.14 million tons in Pakistan. The production of portland concrete is very time consuming and energy consuming process [9].

'Calcinations' is a process in which clay and limestone are heated at $1450^{\circ} \mathrm{C}$, and cement is a mixture of limestone and clay produces after the process of calcinations and is a powdery material in nature. Concrete is a mixture of cement, gravel, sand and water and cement is the main component of concrete and is used as binding agent. Concrete is durable, cheap and easily available in market, this is the reason that it is used as construction material in worldwide [14].Cement industry consumes $10-15 \%$ cement based adhesive material, $70-75 \%$ natural rocks and $15 \%$ water, that is why this industry is the biggest industry for consuming the natural resources. Cement production causes noise pollution by operating machinery, by emitting the airborne particles and greenhouse gases, it cause the air pollution and many other environmental pollutions at the stages of its manufacturing. Cement industry emits 5\% anthropogenic $\mathrm{CO} 2$, among that $40 \%$ is emitted during fossil fuels use, and during the chemical process $50 \%$ is emitted [2].

During the cement production, many toxic heavy metals like thallium, cadmium and mercury are produced, and except this, during the production of $1000 \mathrm{~kg}$ of cement, $900 \mathrm{~kg}$ of $\mathrm{CO} 2$ is emitted. As a result of increasing the human population, there is a need of more construction for living, ultimately increase the environmental pollution and other health hazards [7]. In different industries, during the burning process of coal and wood, Ash is left as residue. The electricity power generation 
houses in Pakistan, which use coal as a fuel, ash is highly obtained from these power houses. In sugar mills, where the sugar fibers are burnt for the electricity power generation, million tons of the fly ash is produced from these mills. Annually Pakistan produced the 6102000 tons of coal ash while 25000 tons of wood [8].

Because of the pozzolanic behavior of ash, it is used in concrete production, for producing the low cost and light weight concrete. Ash can also be produced with the help of rubber, wood saw, wood, coal burning and brick kilns etc. Fly ash causes many health hazards issues by flying in the air, causing the air pollution, causing the environmental pollution [4]. For the production of concrete, fly ash can be used as cost effective and environmental friendly technique. To enhance the binding properties for the production of concrete, we can replace the cement with fly ash, because ash compounds have the binding properties, and also the ash particles are round and very similar in size with cement particles. Simply we can save the industrial waste, sand and cement by using the fly-ash [5].

Light weight aggregate concrete offers the environmental advantages, because it is versatile and an imperative material, and it is expected, this concrete can further help in twisting up the over-aching material for coming decades. The light weight concrete has various applications in floors, window decoration dividers, given way plates, ranges, shell house-tops, in extensive variety of precast elements and also in multi-story building houses. To reduce the dead weight of structure, light weight aggregate concrete is used [13]. The buildings which are being destroyed by the earthquakes, which have ultimately negative impact on civil engineering structures, this concrete can help to reduce the earthquake destroying risks. Higher quality/weight extent, better moldable strain limit, lower coefficient of warm augmentation and unrivaled warmth and sound partition properties because of air voids of the light weight sums are central purposes of helper lightweight aggregate bond [1]. So in this study we produce low cost and environment friendly mortar by adding coal, Vachellia nilotica (kikar) and Dalbergia sissoo (shisham) ash.

\section{MATERIAL AND METHODS}

Following materials were used during this research work for experimental purpose.

\section{A. Materials}

Ordinary Portland cement (OPC) was used for experimental purpose due to locally available in Pakistan. OPC is commonly used in concrete for construction purposes. Cement used for experiment purpose was bought from market. Before using in experiment sieve analysis of cement was conducted to find out the size of cement. Fine aggregate also known as sand which usually occurred in river, lake, sea and those areas where flood had happened. It is easily available in all countries like Pakistan. For manufacturing of concrete standard ratio was used as 1:2:3. In which 2 part of total weight sand was used. In concrete strength sand play important role to fill the pores in concrete. Almost 30\% volume of concrete consists on sand [12].

Gravels also known as coarse aggregate used in concrete and play an important role to enhance the strength of concrete for construction purpose [10]. For manufacturing of concrete standard ratio was used as 1:2:3, in which 4 part of total weight of gravel was used. For experimental purpose different ashes were taken from different industries in Faisalabad (Toseef Housery, Rasheed Textile Mills Ltd, and some local Sizing Mills) which includes coal, Vachellia nilotica (kikar) and Dalbergia sissoo (shisham) ash.

\section{B. Samples prepartaion and Curing}

Multi stage random sampling technique was used for sampling. Fly ash was added in the samples with the proportion of 10, 20, 30, 40 and 50\%. All the samples were cured in a water tank for four different time periods including 7, 14, 21 and 28 days [6]. Different samples of concrete were prepared with ratio 1: 2: 3 in which 1 part of gravel, 2 parts of cement and 3 parts of sand were used. So we prepare the samples according to shape and size of die [16]. For preparing sample tiles die was used for compressive strength and according the shape and size of machine the die was prepared and samples of almost $1000 \mathrm{~g}$ weight were prepared.

\section{Testing}

For measuring tensile strength of the samples Tensile testing machine was used and for measuring the compressive strength concrete testing machine was used [11]. Before testing all the samples were taken out from water tank 3 hours before testing procedure and all the testing were done at room temperature.

\section{RESULTS AND DISCUSSION}

\section{A. Tensile Strength}

Total 216 briquettes samples were prepared to measure the tensile strength of samples. Briquettes tensile strength was measured using a cement testing machine with different percentages of Coal Ash, Vachellia nilotica (kikar) ash, Dalbergia sissoo (shisham) ash as a partial cement replacement are listed below.

\section{1) Tensile Strength of Briquettes Containing Coal Ash}

Fig.1 defines the average values of briquettes tensile strength containing different proportions of coal ash as a partial replacement of cement. Total 24 specimens of three replicates were tested as a partial substitution of cement for the tensile strength test with different proportions of coal ash 0, 10, 20, 30, 40 and $50 \%$. According to the findings during 7, 14, 21 and 28 days of curing, the $10 \%$ coal ash replacement showed better results than all other treatments at 28 days $2.72 \mathrm{MPa}$. While the samples with 20,30, 40 and 50\% coal ash begin to decrease with respect to the 28-day curing treatment. Whereas the samples amended with coal ash of $20 \%$ ratio has strength closest to $10 \%$ replacement $2.51 \mathrm{MPa}$, similarly 30,40 and $50 \%$ showed less tensile strength than $20 \%$ amendment and minimum tensile strength $(1.98 \mathrm{MPa})$ as achieved by replacing coal ash up to $50 \%$ with 28 days curing. As the \% of amendment was increased above 10 percent, there was significant reduction in tensile strength of samples as shown in figure 1 . The findings were the same as the results of [18]. 


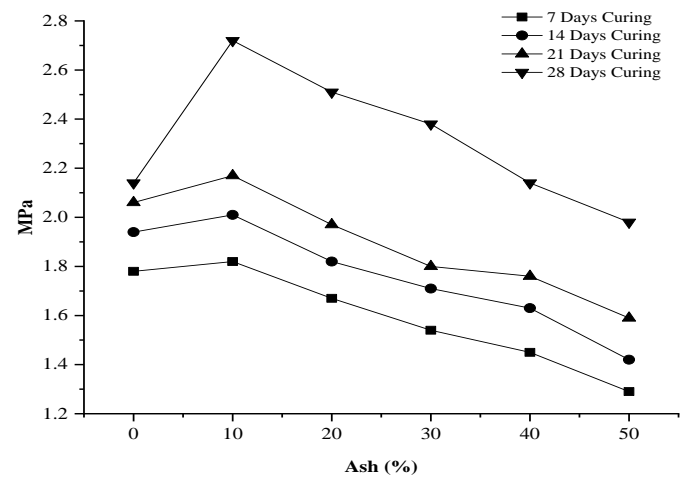

Fig.1: Tensile strength of briquettes Containing Coal Ash in MPa.

\section{2) Tensile Strength of Briquettes Containing Vachellia} nilotica (Kikar) Ash

Fig.2 represent the mean values of briquettes tensile strength containing different percentages of Vachellia nilotica (Kikar) ash as a partial cement substitute. Total 24 samples of three concrete replicates were tested as a partial substitution of cement for the tensile strength with different proportions of vachellia nilotica (Kikar) ash 0, 10, 20, 30, 40, and 50\% cured for 7, 14, 21 and 28 days, according to the results the amendment of $10 \%$ cured for 28 days showed the significant results of $2.49 \mathrm{MPa}$. When using the vachellia nilotica (kikar) ash the tensile strength of the 20,30,40, and $50 \%$ ratio begins to decrease with respect to the 28 days curing. While the $20 \%$ ash showed $(2.03 \mathrm{MPa})$ tensile strength which was lesser than of $10 \%$ amendment similarly $30 \%$ showed a lower tensile strength than the $20 \%$ and $50 \%$ replacement showed the minimum tensile strength of $(1.88$ $\mathrm{MPa})$. The results we obtained were identical to findings of [3].

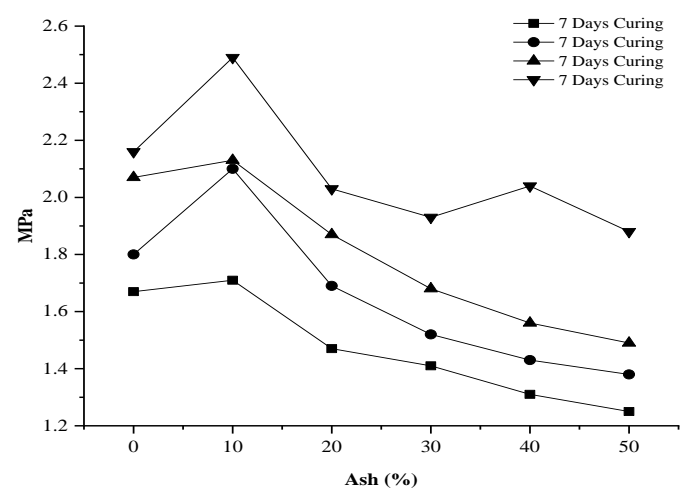

Fig. 2: Tensile Strength of Briquettes Containing Vachellia nilotica (Kikar) Ash

3) Tensile Strength of Briquettes Containing Dalbergia sissoo (shisham) Ash

Fig.3 defines the mean values of briquettes tensile strength containing the different percentage of dalbergia sissoo (shisham) ash as a partially replaced by ordinary Portland cement. Total 24 samples with three replications were analyzed as a partially replaced of cement for the tensile strength test with different proportions of Dalbergia sissoo (shisham) ash 0, 10, 20, 30, 40 and $50 \%$ with different curing of $7,14,21$ and 28 days.
Amendments showed better results than the controlled treatment and according to the results samples partially replaced by $10 \%$ Dalbergia sissoo (shisham) ash has the significant result of 2.12 MPa cured for 28 days. When dalbergia sissoo (shisham) ash concentration was increased to 20,30, 40 and $50 \%$ the tensile strength of briquettes started decreasing with regard to 28 days curing time. $30 \%$ showed the lower tensile strength than the $20 \%$ ratio, this indicate that as the percentage of dalbergia sissoo (shisham) ash increases above $10 \%$, the tensile strength of the briquettes decreases and the lower tensile strength and it was found by $50 \%$ replacement of dalbergia sissoo (shisham) ash the minimum tensile strength $(1.58 \mathrm{MPa})$ was obtained which was the least value as compared to all other treatments. The results we obtained were similar to the finding of [15]

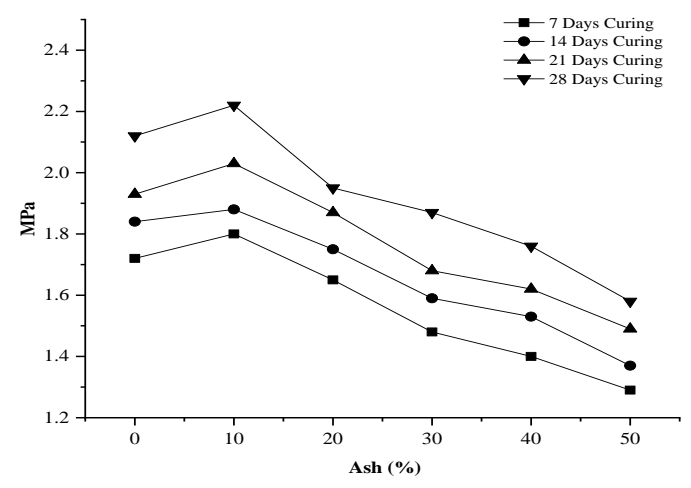

Fig.3 Tensile Strength of Briquettes Containing Dalbergia sissoo (shisham) Ash

\section{B. Compressive Strength}

Taking into account the above findings of the tensile strength of Coal, vachellia nilotica (Kikar) and dalbergia sissoo (Shisham) ash, we obtain the significant tensile strength by using coal ash, so to proceed further we partially substitute the cement only with coal ash for evaluating the compressive strength of concrete.

Fig.4 describes the mean values of compressive strength of tiles containing the different percentages of coal ash as a partial replacement of (OPC) cement. Total 24 specimens of three replicates were tested as a partial substitution of cement for the compressive strength with different proportions of amendment $0,10,20,30,40$ and 50. According to the results the control procedure showed the best results in 7, 14, 21 and 28 days of curing compared to all other amendments (38.75 MPa). The samples having $10 \%$ coal ash showed the best performance of (40.83 MPa) compressive strength cured for 28 days. While the results of $20 \%$ coal ash replacement was close to the control treatment $(35.37 \mathrm{MPa}) .30 \%$ amendment showed a lower compressive strength than $20 \%$, likewise $40 \%$ and $50 \%$ both showed a lower tensile strength than $30 \%$ and the least compressive strength $(22.59 \mathrm{MPa})$ was noticed when the amount of amendment was increased to $50 \%$ cured for 28 days. As the percentage age of coal ash rises above $10 \%$, it indicates that the compressive strength of the tiles begins to decline. The similar results were obtained in the study by [17]. 


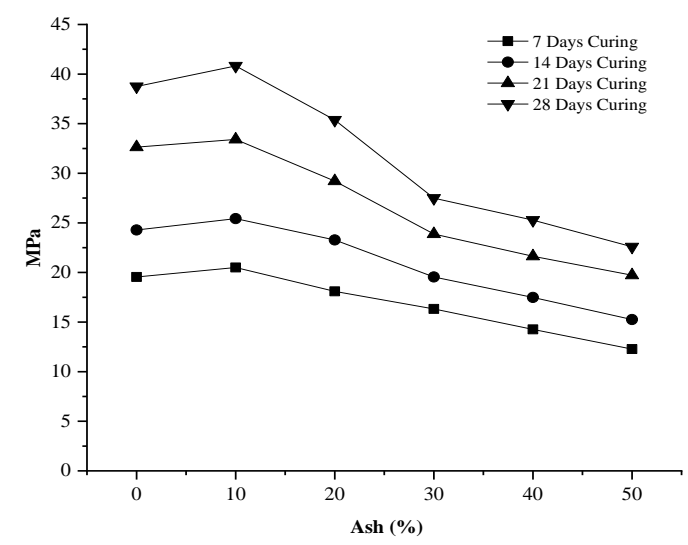

Fig.4 Compressive Strength of Tiles Containing Coal Ash

\section{CONCUSLION}

Based on the results of tensile and compressive strength of this experimental study, it was concluded that Fly ash could be used for the production of light weight concrete and the use of fly ash in concrete can reduce the environmental pollution. The coal ash can make the concrete of (40.83 MPa) strength which is light weight strengthened. Finally this technique is an environmental friendly and it can reduce the risk of earth quick damage in the locality.

\section{ACKNOWLEDGMENT}

The author wish to express the gratitude to his supervisors for their continuous support throughout the study and National Highways Authority (NHA), Faislaabad, Pakistan for helping to perform tests in their laboratory.

\section{REFERENCES}

[1] Aragão, F. (2007). Effects of aggregates on properties and performance of mastics and superpave hot mix asphalt mixtures.J. Clerk Maxwell, A Treatise on Electricity and Magnetism, 3rd ed., vol. 2. Oxford: Clarendon, 1892, pp.68-73.

[2] Benhelal, E., Zahedi, G., Shamsaei, E., \& Bahadori, A. (2013). Global strategies and potentials to curb $\mathrm{CO} 2$ emissions in cement industry. Journal of cleaner production, 51, 142-161.

[3] Cheah, C. B., \& Ramli, M. (2011). The implementation of wood waste ash as a partial cement replacement material in the production of structural grade concrete and mortar: An overview. Resources, Conservation and Recycling, 55(7), 669-685.

[4] Dmitrienko, M. A., \& Strizhak, P. A. (2018). Coal-water slurries containing petrochemicals to solve problems of air pollution by coal thermal power stations and boiler plants: An introductory review. Science of the Total Environment, 613, 1117-1129.

[5] Drochytka, R., Zach, J., Korjenic, A., \& Hroudová, J. (2013). Improving the energy efficiency in buildings while reducing the waste using autoclaved aerated concrete made from power industry waste. Energy and Buildings, 58, 319-323.

[6] Formosa, L. M., Mallia, B., Bull, T., \& Camilleri, J. (2012). The microstructure and surface morphology of radiopaque tricalcium silicate cement exposed to different curing conditions. Dental Materials, 28(5), 584-595.

[7] Kampa, M., \& Castanas, E. (2008). Human health effects of air pollution. Environmental pollution, 151(2), 362-367.
[8] Kazmi, Syed MS, Safeer Abbas, Muhammad A. Saleem, Muhammad J. Munir, and Anwar Khitab. "Manufacturing of sustainable clay bricks: Utilization of waste sugarcane bagasse and rice husk ashes." Construction and building materials 120 (2016): 29-41.

[9] Madlool, N. A., Saidur, R., Hossain, M. S., \& Rahim, N. A. (2011). A critical review on energy use and savings in the cement industries. Renewable and Sustainable Energy Reviews, 15(4), 20422060.

[10] Meddah, M. S., Zitouni, S., \& Belâabes, S. (2010). Effect of content and particle size distribution of coarse aggregate on the compressive strength of concrete. Construction and Building Materials, 24(4), 505-512.

[11] Pascale, G., Di Leo, A., \& Bonora, V. (2003). Nondestructive assessment of the actual compressive strength of high-strength concrete. Journal of Materials in Civil Engineering, 15(5), 452-459.

[12] Qian, Z., Garboczi, E. J., Ye, G., \& Schlangen, E. (2016). Anm: a geometrical model for the composite structure of mortar and concrete using real-shape particles. Materials and Structures, 49(1-2), 149-158.

[13] Sajedi, F., \& Shafigh, P. (2012). High-strength lightweight concrete using leca, silica fume, and limestone. Arabian journal for Science and engineering, 37(7), 1885-1893.

[14] Schneider, M., Romer, M., Tschudin, M., \& Bolio, H. (2011). Sustainable cement production-present and future. Cement and concrete research, 41(7), 642-650.

[15] Siddique, R. (2012). Utilization of wood ash in concrete manufacturing. Resources, conservation and Recycling, 67, 27-33.

[16] Wang, H. T., and L. C. Wang. "Experimental study on static and dynamic mechanical properties of steel fiber reinforced lightweight aggregate concrete." Construction and Building Materials 38 (2013): 1146-1151.

[17] Wongkeo, W., \& Chaipanich, A. (2010). Compressive strength microstructure and thermal analysis of autoclaved and air cured structural lightweight concrete made with coal bottom ash and silica fume. Materials Science and Engineering: A, 527(16-17), 3676-3684.

[18] Yasar, E., Atis, C. D., Kilic, A., \& Gulsen, H. (2003). Strength properties of lightweight concrete made with basaltic pumice and fly ash. Materials Letters, 57(15), 2267-2270. 